\title{
Distinct Pathways for Rule-Based Retrieval and Spatial Mapping of Memory Representations in Hippocampal Neurons
}

\author{
Rapeechai Navawongse and Howard Eichenbaum \\ Center of Memory and Brain, Boston University, Boston, Massachusetts 02115
}

\begin{abstract}
Hippocampal neurons encode events within the context in which they occurred, a fundamental feature of episodic memory. Here we explored the sources of event and context information represented by hippocampal neurons during the retrieval of object associations in rats. Temporary inactivation of the medial prefrontal cortex differentially reduced the selectivity of rule-based object associations represented by hippocampal neuronal firing patterns but did not affect spatial firing patterns. In contrast, inactivation of the medial entorhinal cortex resulted in a pervasive reorganization of hippocampal mappings of spatial context and events. These results suggest distinct and cooperative prefrontal and medial temporal mechanisms in memory representation.
\end{abstract}

\section{Introduction}

Recent experimental studies seeking to characterize the nature of neural representations that support context-guided memories in animals have focused on the hippocampus. These studies have shown that representations of events by CA1 neurons are modulated by the spatial and temporal context in which the events occur (Komorowski et al., 2009; Kim et al., 2011; MacDonald et al., 2011). Here we examined the origin of context selectivity in memory representations encoded by hippocampal neurons. There is substantial recent evidence indicating that the medial prefrontal cortex (mPFC) coordinates with the hippocampus in supporting context-dependent memory in humans (Buckner and Wheeler, 2001; Dobbins et al., 2002; Dickerson et al., 2007; Blumenfeld et al., 2011) and animals (Hyman et al., 2005; Lee and Solivan, 2008; Barker and Warburton, 2011; Colgin, 2011; Gordon, 2011). Studies on humans emphasize the executive functions of the PFC in memory retrieval, including "top-down" control over memory retrieval by biasing memory representations in cortical areas (Tomita et al., 1999) and the hippocampus (Cohen et al., 1996), and studies in monkeys and rats also indicate that PFC guides retrieval according to ongoing task rules (Miller, 1999; Rich and Shapiro, 2009). In contrast, other studies (Colgin, 2011; Gordon, 2011) emphasize direct projections from the hippocampus to the $\mathrm{mPFC}$ and suggest that the hippocampus generates memory representations that the PFC reconciles with current task demands to guide behavioral choices (Buckner and Wheeler, 2001; Dobbins et al., 2002). Other views include both

\footnotetext{
Received Aug. 14, 2012; revised 0ct. 20, 2012; accepted 0ct. 26, 2012.

Author contributions: R.N. and H.E. designed research; R.N. performed research; R.N. analyzed data; R.N. and H.E. wrote the paper.

This work was supported by Silvo 0. Conte award MH094263 and ONR MURI award N00014-10-1-0936.

Correspondence should be addressed to Howard Eichenbaum, Center of Memory and Brain, Boston University, 2 Cummington Street, Boston, MA 02115. E-mail: hbe@bu.edu.

DOI:10.1523/JNEUROSCI.3891-12.2013

Copyright $\odot 2013$ the authors $\quad 0270-6474 / 13 / 331002-12 \$ 15.00 / 0$
}

directions of processing (Buckner and Wheeler, 2001; Simons and Spiers, 2003). In addition, the medial entorhinal cortex (MEC) has been suggested as the origin of maps of spatial context, which are conveyed to the hippocampus where events are represented within a spatial framework (Manns and Eichenbaum, 2006; Moser et al., 2008; Hasselmo et al., 2010). The roles of $\mathrm{mPFC}$ and MEC might operate via separate influences of rulebased memory retrieval and organization of events within spatial contexts, respectively, or they might interact, for example, via $\mathrm{mPFC}$ biasing retrieval of spatial representations in MEC, which in turn organizes hippocampal representations.

Here we trained rats to employ a spatial-contextual rule to guide object choices and examined whether temporary inactivation of mPFC or MEC alters the retrieval of object or spatial representations as reflected by neural activity patterns in the hippocampus. If memory retrieval involves an essential flow of information from PFC to the hippocampus, then mPFC inactivation should affect memory performance and alter hippocampal firing patterns that signal memories for particular events associated with specific places. In contrast, if the MEC provides a spatial representation that is separate from the mPFC influence, inactivating MEC should affect performance and result in global alternations of spatial representation including how events are mapped in space. Alternatively, if $\mathrm{mPFC}$ influences the hippocampus via MEC, then $\mathrm{mPFC}$ inactivation should alter spatial as well as object mappings.

\section{Materials and Methods}

A total of 11 8- to 12-month-old male 350-450 g Long-Evans rats were used, 5 in experiments using MEC inactivation and 6 in experiments on $\mathrm{mPFC}$ inactivation. All rats were obtained from the Charles River Laboratory and maintained in Boston University's Laboratory Animal and Care Facility. The Boston University Institutional Animal Care and Use Committee approved all the surgical and experimental procedures performed in this study.

Behavioral training. The behavioral protocol was similar to that described in a previous study (Komorowski et al., 2009). Each rat was 


\section{Context A Context B}

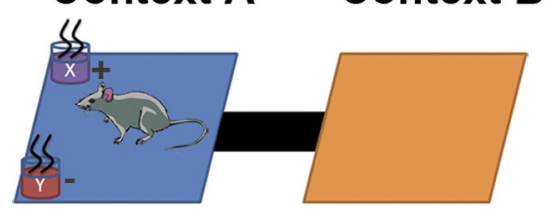

Figure 1. Context-guided object discrimination task. Rats initially move into one of two environmental contexts (A or B) and explore without the presence of object stimuli for $20 \mathrm{~s}$. Then two objects $(X, Y)$ are placed in two corners of the context; the left-right positions of $X$ and $Y$ are pseudorandomized across trials. In Context $A$, object $X$ is baited $(+)$ and $Y$ is not $(-)$, whereas in Context $B$, object $Y$ is baited and $X$ is not.

initially pretrained to perform a simple object discrimination task before learning the context-guided object association task. The object stimuli were composed as $10 \mathrm{~cm}$ height and $11 \mathrm{~cm}$ diameter terra cotta flowerpots were filled with fine grain playground sand. Two types of oil fragrance (lemon and peppermint at $2 \%$ in vegetable oil) were applied around the edge of each flowerpot. In this pretraining task, on each trial the two pots were presented at pseudorandomly selected different corners in the animal's home cage, and rats learned to choose the pot with peppermint scent to obtain a one-quarter Froot Loop reward buried beneath the sand surface; the lemon-scented pot did not contain a reward. Forty trials were conducted each day until performance reached $80 \%$ correct in the last 10 trials of one session.

The apparatus used for the context-guided object association task consisted of two $45 \times 40 \mathrm{~cm}$ context-boxes, with walls tilted $35^{\circ}$ to the horizontal plane in all directions, separated by $20 \mathrm{~cm}$ wide connecting path (Fig. 1). The two contexts were visually distinguished by wallpaper surrounding the four sides of each box (red horizontal stripes vs blue vertical stripes) and long black curtains were hung around all four sides of the maze to minimize distal clues. The stimulus objects were two flowerpots distinguished by scent (grapefruit vs geranium; AuraCacia) and by the medium (purple beads vs white foam bits) that filled the pots in which rats dug to obtain rewards. During the first $2 \mathrm{~d}$ in this task, rats were familiarized with the apparatus by allowing them to forage for a Froot loop reward located at each of the four corners inside the maze for 20 min each day.

The training for the context-guided object association task began the next day. On each trial both pots were presented in pseudorandomized left-right positions in distant corners of one of the contexts. In the context with red horizontal striped wallpaper, the flowerpot with germanium scent contained one-quarter Froot loop. In the context with blue vertical striped wallpaper, the flowerpot with grapefruit scent contained the reward. At the beginning of each trial, rats were allowed to enter one context and explore it without the pots present for $20 \mathrm{~s}$ (the context exploration period), after which the two flowerpots were positioned and a divider prohibited movement between boxes during the remainder of the trial (the object-sampling period). During the first two days, rats were allowed to dig in both pots until they obtained the reward. Subsequently, the rat was allowed to move into the other context and the next trial began. After the first two days, the rat was allowed to dig in only one pot such that, when the rat's nose or paw touched the surface of the media in the unbaited flowerpot, both pots were removed and a $5 \mathrm{~s}$ time out ensued, and training continued with blocks of five trials in the same context before alternating. Fifty to sixty trials were performed each day during the training phase. When performance reached $70 \%$ correct in a session, the number of trials per block was reduced to three and then to one, such that trials alternated between the two contexts except that two consecutive trials occurred randomly in the same context every 10 trials. Then rats were allowed to rest for 1 week before implant surgery.

Cannula and infusion system and electrode implantations. Animals were implanted with cannulae bilaterally in $\mathrm{mPFC}$ or MEC and a tetrode array bilaterally in CA1. The cannulae (G313C; Plastics One) included guide tubes, attached with a dummy cap (C313DC-1; Plastics One), that protruded $2 \mathrm{~mm}$ from the end of the cannulae. Cannulae were implanted bilaterally into either $\mathrm{mPFC} \mathrm{(} 3 \mathrm{~mm}$ anterior and \pm 2.5 lateral to bregma, inserted $2.5 \mathrm{~mm}$ below the surface at $\pm 20^{\circ}$ angle to the sagittal plane) or MEC ( $0.2-0.5 \mathrm{~mm}$ posterior to sinus suture, $\pm 5.5 \mathrm{~mm}$ lateral to bregma, icon tube and the location of the plunger.

and $3.4 \mathrm{~mm}$ below dura surface (Sauvage et al., 2008). The injection system consisted of a micro syringe (7633-01; Hamilton) connected to an internal injection tube (C313I; Plastic One) via a silicone tube filled with mineral oil. A syringe pump (UMD3; World Precision Instrument) and pump controller (micro4 micro syringe pump controller; World Precision Instrument) were used to infuse the solution in steady flow $(0.3 \mu \mathrm{l} / \mathrm{min})$ and precise volume $(0.4 \mu \mathrm{l})$. The infusion tubes were left at the infusion sites for $2 \mathrm{~min}$ then replaced by a dummy cap. The infusion was verified by examining the level of the solution within the sil-

Tetrodes were made by spinning four $12.5 \mu \mathrm{m}$ nichrome wires together, and were arranged in two groups of six tetrodes implanted in each hemisphere. The tips of the wires were plated with gold to reduce impedance to $180-220 \mathrm{k} \Omega$ at $1 \mathrm{kHz}$. Each headstage included 12 moveable tetrodes distributed bilaterally above CA1 ( $3.5 \mathrm{~mm}$ posterior and \pm 1.6 lateral to bregma). A ground wire was connected to a screw fixed to the skull plate. Rats were allowed to recover for 1 week following surgical implantations. Neural activity was amplified $(4000-8000 \times)$ and filtered $(100-6000 \mathrm{~Hz})$ before recording in the Omniplex system (Plexon).

Before recording, rats were retrained to perform the context-guided object association task until performance reached $90 \%$ correct within a day (40 trials). During the training period, tetrode wires were lowered to the pyramidal layer of CA1. The location of the layer was located by counting the number of turns to lower the tetrodes and observation of sharp wave ripples and theta modulation in the local field potential. The series of inactivation conditions described below were conducted after performance criterion was reached and the tetrode wires were located at pyramidal layer of CA1.

Behavioral testing, infusions, and recording. Five conditions were examined on consecutive days with at least a $12 \mathrm{~h}$ separation between conditions. Each day began with a 30 trial session where the animal performed the task and recordings were taken. Then an infusion was performed and the animal was returned to the home cage for $30 \mathrm{~min}$. Finally, another 30 trial recording session was performed. The conditions differed by the type of infusion (saline or $1 \mathrm{mg} / \mathrm{ml} \mathrm{muscimol}$ ) and whether the infusions were bilateral or ipsilateral to the recording electrode site, and were performed in the following order: no injection, bilateral saline injection, bilateral muscimol injection, left-side unilateral injection, and right-side unilateral injection. For unilateral infusions, muscimol solution was infused on one side while saline solution was infused into the other side. On the first recording day, during the intersession period, the cannula caps were removed and replaced, but no injection was performed. On the second day, during the intersession period, saline was infused bilaterally into either $\mathrm{mPFC}$ or MEC and the rat was allowed to rest for the remainder of $30 \mathrm{~min}$ before continuing the second session. On subsequent days, muscimol, a GABA agonist that silences neural activity for several hours, was infused bilaterally or unilaterally into $\mathrm{mPFC}$ or MEC during the intersession period (Fig. 2).

Behavioral analyses. The effects of treatments on performance accuracy on the context-guided association task were assessed by paired $t$ tests comparing the percentage correct choices between conditions. In addition, to explore whether object-sampling behavior was affected by the treatments, we measured the total time between onset of the object-sampling period and object choice (digging) and compared times using a $Z$-test, which determines the probability that the distributions in object-sampling time are drawn from the same normal distribution. Also, we examined whether treatments increased the number of trials in which animals sampled objects four or more times before making their choice, and the distributions of oversampling events were compared with $\chi^{2}$ analyses.

Histological identification of cannulae and electrode locations. At the end of experiment, rats were euthanized with an overdose of pentobarbital. The recording locations were verified by passing through $40 \mu \mathrm{A}$ current through tetrodes for $40 \mathrm{~s}$. The infusion sites were verified by infusing fluorescent muscimol ( $1 \mathrm{mg} / \mathrm{ml}$ in sterile saline, M23400; Invitrogen) 
before perfusion with $10 \%$ formalin (Allen et al., 2008). The time between the infusion and perfusion was at least $15 \mathrm{~min}$. Each brain was stored in $30 \%$ sucrose until it sank at $4^{\circ} \mathrm{C}$, and then sliced along sagittal plane for MEC group and coronal plane for mPFC group at $40 \mu \mathrm{m}$ thickness. Tips of the infusion cannulae were visualized by Nissl stain (Fig. $2 A$ ), the spread of muscimol solution was identified under a fluorescent microscope (Fig. 2B), and the tip positions were confirmed as localized in MEC or mPFC (Fig. 2C).

Single neuron analyses. Spike activity was recorded and analyzed off-line after the experiment. Single unit activity was isolated based on spike properties (valley, peak) and principal components of the waveform by Offline Sorter software (Plexon). Single-unit spike activity from two sessions was analyzed at the same time to ensure that the same cell was isolated. Time stamps of spike activity were saved and exported to MATLAB. The location of the rat was tracked through two light emitting diodes (blue and red) located on head-stage during both sessions of the experiment. The video time stamp $(30 \mathrm{~Hz})$ was synchronized with the spike activity recording time. The video frames $(360 \times 640$ pixels $)$ where rats entered the box and sampled the flowerpot were marked for further analyses.

Analyses of object-sampling responses. Neurons that responded during object-sampling bouts ( $1 \mathrm{~s}$ before and after rats' nose reached the edge of the pots) were further classified for object-specific firing. Three-way ( 2 objects $\times 4$ positions $\times$ before vs during object sampling) ANOVA was used to identify neurons that responded during the object-sampling bouts. Notably, these analyses focused on differences in firing patterns during object sampling among the four positions where objects were presented, rather than on comparing responses across the two contexts (or position as a nested variable within context) that guided object choices, because hippocampal neurons typically fire differently at each position, and sometimes have distinct firing patterns within both contexts (see Fig. 4, Unit 5). Neurons that had significant $(p<0.05)$ variation on any of the main factors or interactions were considered in additional analyses. Raster plots and peri-event histograms were plotted for $1 \mathrm{~s}$ before and after stimulus sampling period associated with each combination of an object (flowerpots with grapefruit and germanium) and position (left or right corner of either of the two contexts). Also, for all object-sampling cells, spatial firing maps were plotted for the entire session (including both the context exploration and object-sampling periods) using methods described below.

The stability of firing patterns during object sampling across the two sessions was evaluated by calculating a Pearson correlation coefficient that compared the mean firing rates between the two sessions during object sampling among the eight combinations of two objects and four positions. This analysis revealed a bimodal distribution of correlations indicating that neurons were generally either relatively stable or substantially changed between the two sessions. We then used an unsupervised K-means algorithm to identify the threshold value that best separated the stable and changed sample clusters. The K-means algorithm sorted all samples into two clusters that best minimized the sum of the distances between each sample point and its clustering center. We identified neurons as stable if their correlation coefficient fell
mPFC

A

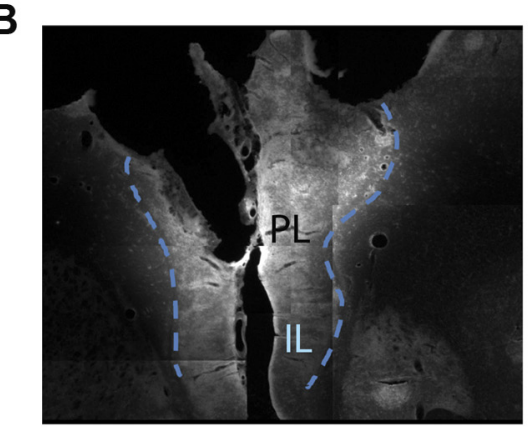

C

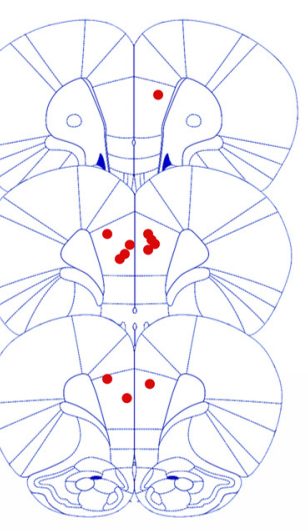

MEC
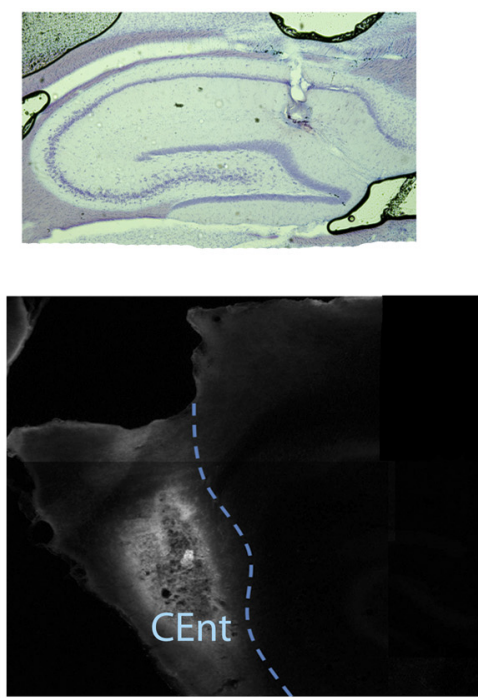

Left

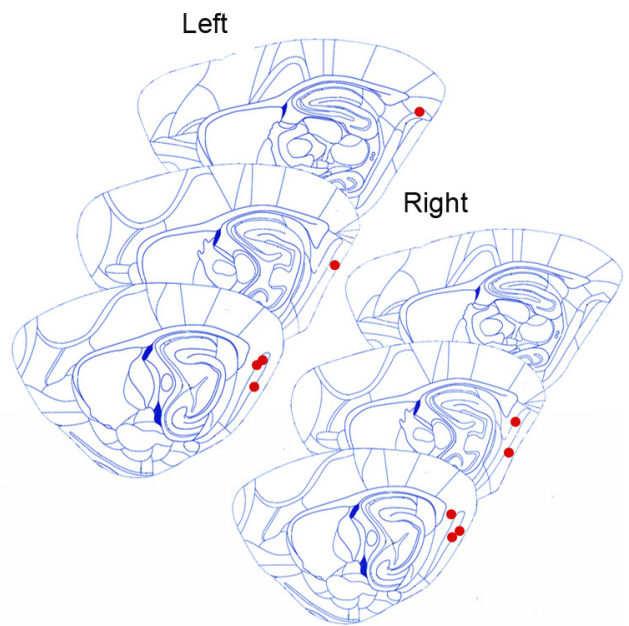

Figure 2. A, Lesion marks made at tips of tetrodes located in CA1 of one rat from the $\mathrm{MPFC}$ group and one from the MEC group. The slices obtained from mPFC group were in the coronal plane and those from the MEC group were in the sagittal plane. $\boldsymbol{B}$, Fiscion deposition at injection sites. The left image shows cannula track and deposition in $\mathrm{mPFC}$, while the right s cannula tracks and deposition in MEC. The bright area localizes the muscimol deposition in each area. C, Histological plates showing locations of bilateral cannula in both $\operatorname{mPFC}(n=6)$ and MEC $(n=5)$ groups. Histological plates were adopted from Paxinos and Watson (2010). CEnt, caudal medial entorhinal cortex; PL, prelimbic; IL, infralimbic.

above the threshold or changed if it fell below, and used $\chi^{2}$ tests to determine whether the percentage of cells with stable responses during object sampling differed across experimental conditions.

In addition, object selectivity indices were computed by $\mathrm{SI}=(X-$ $Y) /$ maximum $(X, Y)$, where $X$ and $Y$ are the mean firing rates associated with the two objects at the position associated with the maximum firing rate, thus providing a normalized measure of object selectivity. If the mean firing rate for either $X$ or $Y$ was $<1 \mathrm{~Hz}$, the rate was threshold to zero to eliminate the possibility of false object selectivity. Differences in SIs between the two sessions were computed by subtracting the SI from session 1 with that in session 2. Because the distributions of SI differences were not normal, as indicated by goodness-of-fit tests, we applied a threshold of SI $=0.3$ as the minimum in the overlap of the distributions for separating neurons that were stable versus changed in object selectivity. Then $\chi^{2}$ tests were used to compare the distributions of the SI differences between experimental conditions.

Analyses of spatial firing patterns. Maximum firing rate was calculated as the firing rate at the spatial bin with the highest rate. Spatial selectivity was computed by dividing the maximum firing rate by the mean firing rate within the place fields. Spatial sparsity was computed by dividing 
square mean rate with mean square rate over all locations (Skaggs et al., 1996; Treves et al., 1996). Spatial information (Skaggs et al., 1996) was computed by the following:

$$
I=\sum_{i=1}^{n} P_{i} \frac{\gamma_{i}}{\gamma} \log _{2} \frac{\gamma_{i}}{\gamma}
$$

where $\gamma_{i}$ is the firing rate at the $i$ th bin, $\gamma$ is the mean firing rate, and $p_{i}$ is the probability that the rat occupied the $i$ th bin. The effects of treatments on these measures were evaluated using a $Z$-statistic that determines the probability that the distributions of scores are drawn from the same normal distribution.

Spatial firing rate maps were computed using $2 \times 2 \mathrm{~cm}$ bins that were visited at least three times and for $>1 \mathrm{~s}$ during both sessions within an experiment. For analyses of spatial firing patterns during the period when the rat explored a context, only data during the beginning of the trial to $1 \mathrm{~s}$ before object sampling were included. Firing rates for each bin were computed by dividing the total number of spikes by the time spent in the bin; spikes were included if the rat was moving at a velocity $>10$ $\mathrm{cm} / \mathrm{s}$. Spatial firing patterns were smoothed with a 2D Gaussian filter $(\sigma=1)$. Bins were included in the place field, if and only if the firing rate was $>20 \%$ of the bin with maximum firing rate. Place field size was computed by counting the number of bins that had a mean firing rate $>20 \%$ of the maximum firing rate. Neurons were considered to have a place field if, within at least one session, they had a maximum mean firing rate $>1 \mathrm{~Hz}$, sparsity $<0.8$, and size $<450$ bins. The mean firing rate was computed as the average of the firing rates of each bin within place fields ( $>20 \%$ spatial maximum firing rate).

The similarity of place fields between the two sessions based on Pearson's correlations were computed as follows:

$$
r=\frac{\sum_{i=1}^{n}\left(\gamma_{i}-\gamma\right)\left(\beta_{i}-\beta\right)}{\sqrt{\sum_{i=1}^{n}\left(\gamma_{i}-\gamma\right)^{2}} \sqrt{\sum_{i=1}^{N}\left(\beta_{i}-\beta\right)^{2}}}
$$

where $\gamma_{i}$ is the firing rate at the $i$ th bin in session $1, \gamma$ is the mean firing rate in session $1, \beta_{i}$ is the firing rate at the $i$ th bin in session 2 , and $\beta$ is the mean firing rate in session 2 (Muir and Bilkey, 2001; Sava and Markus, 2008; Van Cauter et al., 2008). Bins that had firing rates $<0.3 \mathrm{~Hz}$ were thresholded to zero to prevent false correlations. Only bins that were visited at least three times in both sessions were used. These analyses revealed bimodal distributions of correlations indicating that neurons were generally either relatively stable or "remapped" between the two sessions. Therefore we used an unsupervised K-means algorithm to identify the threshold value that best separated the stable and remapped clusters based on correlation coefficient values and identified neurons as stable if their correlation coefficient fell above the threshold or remapped if it fell below. Then we used $\chi^{2}$ tests to determine whether the proportions of cells with stable fields differed across experimental conditions.

\section{Results}

$m P F C$ and MEC are essential to accurate retrieval of

context-guided object associations

In the no-treatment and saline treatment days (days 1 and 2), accuracy on the task remained above $90 \%$ in both the first and second sessions in both the MPFC and MEC groups (Fig. 3A). On the third day, following muscimol infusion bilaterally into $\mathrm{mPFC}$ or MEC, performance declined significantly in the $\mathrm{MPFC}$ group $\left(t_{(10)}=13.41, p<0.0001\right)$ and in the MEC group $\left(t_{(8)}=3.26, p<\right.$ $0.01)$. On the fourth day, performance recovered back to baseline during the first session in both groups. Subsequent unilateral inactivation on either left (day 4) or right (day 5) hemisphere did not impair performance in either the mPFC group $\left(t_{(10)}=1.3\right.$, $p=0.257$ for left-side infusion; $t_{(10)}=0.194, p=0.85$ for rightside infusion) or the MEC group $\left(t_{(8)}=-0.937, p=0.376\right.$ for left-side infusion; $t_{(8)}=1.00, p=0.342$ for right-side infusion). These results show that both $\mathrm{MPFC}$ and MEC are required to perform the context-guided object association task, but an intact
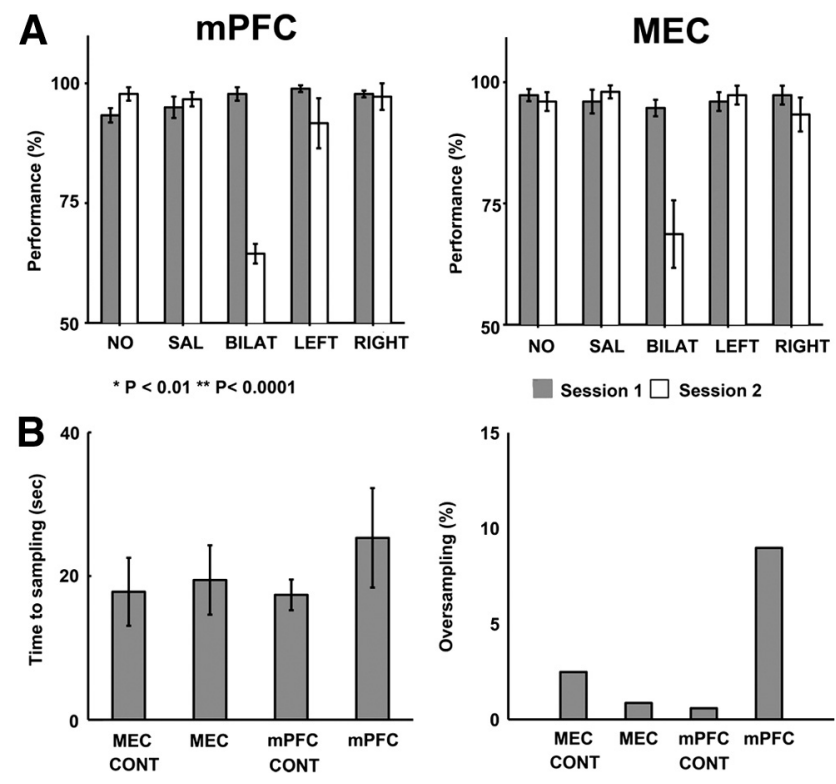

Figure 3. $A$, Comparison of the mean ( \pm SE) performance accuracy on the context-guided object association task between session 1 and session 2 of all five treatment conditions from both MEC and mPFC groups. N0, no injection; SAL, saline injection; BILAT, bilateral muscimol injection; LEFT, unilateral muscimol injection on the left hemisphere; RIGHT, unilateral muscimol injection on the right hemisphere. $\boldsymbol{B}$, Comparisons of behavior during object sampling by control and bilateral mPFC and MEC inactivation groups. Left, Mean \pm SE of time of object sampling before choice. CONT, control group with no treatment and saline infusion combined. Right, Number of trials with four or more object samplings before the choice response.

unilateral pathway is sufficient to support performance (Warburton and Brown, 2010).

Further analyses showed that, even though bilateral mPFC and bilateral MEC inactivation reduced overall performance, the two groups behaved differently during object sampling before making the digging response. Following bilateral mPFC inactivation rats required more time $(25.32 \pm 6.92 \mathrm{~s})$ to make their object choice than in mPFC Control sessions ( $17.38 \pm 2.13 ; z=-6.293$, $p<0.00001)$ and more than on sessions following MEC inactivation $(19.45 \pm 4.83 \mathrm{~s} ; z=2.859, p=0.0046)$, which did not differ from MEC Control sessions (17.81 $\pm 4.73 ; z=-1.618, p=$ 0.107; Fig. 3B, left). Most remarkably, on occasion following bilateral $\mathrm{mPFC}$ inactivation, rats repeatedly sampled the two objects before digging ( $4+$ sampling events on $9.0 \%$ of trials) more often than on mPFC Control (no treatment + saline) sessions $\left(0.6 \% ; \chi^{2}=22.197, d f=1, p<0.00001\right)$ and more than following MEC inactivation $\left(0.9 \%\right.$ of trials; $\chi^{2}=7.563, d f=1, p=$ $0.006)$, which did not differ from MEC Control sessions $(2.5 \%$; $\chi^{2}=1.002, d f=1, p=0.317$; Fig. $3 B$, right). Thus, while both $\mathrm{mPFC}$ and MEC play essential roles in context-guided memory retrieval, $\mathrm{mPFC}$ inactivation results in abnormally extended object sampling before the choice, whereas MEC inactivation does not affect object-sampling behavior.

Inactivation of mPFC impairs retrieval of hippocampal firing patterns that signal specific object-location associations

On average, 187 neurons were recorded among all animals in the $\mathrm{mPFC}$ group and 241 neurons were recorded in the MEC group on each experimental day (Tables 1,2$)$. The neurons recorded from the ipsilateral and contralateral infusions are derived from both unilateral infusion conditions because we recorded CA1 activity from both sides of the hippocampus simultaneously in all conditions. In these analyses we focused on the object-sampling 
Table 1. Number of units recorded in each $\mathrm{mPFC}$ inactivation experiment

\begin{tabular}{lrrrrr}
\hline & NO & SAL & BILAT & IPSI & CONT \\
\hline All & 212 & 223 & 210 & 150 & 138 \\
Object sampling & 71 & 59 & 67 & 50 & 54 \\
\hline
\end{tabular}

N0, no injection; SAL, saline injection; BILAT, bilateral muscimol injection; IPSI, ipsilateral muscimol injection; CONT, contralateral muscimol injection.

Table 2. Number of units recorded in each MEC inactivation experiment

\begin{tabular}{lrrrrr}
\hline & N0 & SAL & BILAT & IPSI & CONT \\
\hline All & 231 & 169 & 264 & 280 & 263 \\
Object sampling & 64 & 52 & 79 & 75 & 80
\end{tabular}

NO, no injection; SAL, saline injection; BILAT, bilateral muscimol injection; IPSI, ipsilateral muscimol injection; CONT, contralateral muscimol injection.

period, measuring mean firing rates $1 \mathrm{~s}$ preceding and during $1 \mathrm{~s}$ object-sampling bouts and spatial firing patterns during the entire period between object presentation and behavioral choice. A three-way ANOVA analysis (see Materials and Methods) was used to identify neurons that fired differentially during objectsampling bouts.

In control conditions (combined $\mathrm{mPFC}$ and MEC saline and no-treatment groups), a total of 253 neurons (29.9\% of all neurons isolated) fired differentially during object sampling in one or both sessions. Many $(n=172 / 253,68 \%)$ of these neurons fired differentially across the four object-sampling positions (two within each context) and many $(n=162 / 253 ; 64.1 \%)$ objectsampling neurons fired differentially during the sampling of one of the objects, and maintained the same object-sampling firing patterns between recording sessions. Examples of objectsampling neurons are shown in Figure 4. Control Units 1, 2, and 3 had clear place fields at object-sampling positions and fired maximally during sampling of particular object-position combinations consistently in the first and second sessions. In Figure 4, Unit 1, was activated during sampling of both stimuli in the upper position in Context B, but fired preferentially during sampling of object X. Unit 2 fired selectively during sampling of object $\mathrm{Y}$ in the lower position in Context A. Unit 3 fired selectively during sampling of object $\mathrm{X}$ in the upper position in Context B.

Following bilateral or ipsilateral mPFC inactivation, many neurons lost object selectivity without a change in place fields around the object-sampling positions. For example, in Figure 4, Unit 4, fired with high selectivity during sampling of object $\mathrm{X}$ rat at the lower position in Context $\mathrm{B}$ during session 1, but also fired during the sampling of object $\mathrm{Y}$ in the same position after $\mathrm{mPFC}$ inactivation in session 2. Unit 5 had two specific object-position firing correlates in session 1 , but fired during the sampling of both objects following mPFC inactivation in session 2. We also observed a minority of object-sampling neurons that ceased firing during the object-sampling period following mPFC inactivation. For example, Unit 6 fired selectively during sampling object $\mathrm{X}$ at the lower position in Context $\mathrm{A}$, but lost selectivity because the unit stopped firing during the object-sampling period. Quantitative characterizations of the effects of mPFC inactivation focused on the extent to which alterations in firing patterns involved changes in the locus of firing and changes in the object selectivity of objectsampling responses.

The effects of mPFC inactivation on firing patterns during object sampling were initially examined by correlating between sessions the mean firing rates during that period across the eight object-position combinations (see Materials and Methods). The distribution of correlation coefficients was bimodal in the combination of all control conditions (no treatment and saline treatment in $\mathrm{mPFC}$ and MEC groups), with peaks at correlation coefficient values of approximately -0.15 and 1.0 , indicating two distinct categories of responses (Fig. $5 A$ ), neurons that were relatively stable between the two sessions and those that substantially altered their firing patterns. To assess differences in the proportions of neurons between these two categories, we used an unsupervised K-means clustering algorithm to identify the best threshold value to separate between two cluster groups as $r=$ 0.38 , then designated neurons that had a correlation coefficient greater than the threshold as stable and neurons with correlations coefficients less than the threshold as altered between sessions, and we then used the $\chi^{2}$ tests to statistically compare the proportions across the experimental conditions within and between groups.

Our initial comparison of no-treatment and saline conditions showed no difference between these conditions $\left(\chi^{2}=0.0267\right.$, $d f=1, p=0.870$ in mPFC group; $\chi^{2}=0.146, d f=1, p=0.702$ in MEC group), therefore the no treatment and saline conditions were combined to compose an $\mathrm{mPFC}$ Control condition that showed strong stability $(n=92 / 130 ; 70.77 \%)$ across sessions. An overall $\chi^{2}$ analysis including the mPFC Control and treatment groups revealed differences among the treatment conditions $\left(\chi^{2}=9.923, d f=3, p=0.0192\right)$. Post hoc tests showed a significant decrease in the proportion of stable neurons after bilateral $\left(n=40 / 67 ; 59.7 \%\right.$ stable; $\left.\chi^{2}=11.69, d f=1, p<0.001\right)$ and ipsilateral mPFC $\left(n=31 / 50 ; 62.2 \%\right.$ stable; $\chi^{2}=7.659, d f=1$, $p<0.01$ ) inactivation compared with the Control group. Following contralateral inactivation, there was no decrease in stability compared with Controls $\left(n=39 / 54 ; 72.2 \% ; \chi^{2}=\right.$ 1.423, $d f=1, p=0.233$ ).

To further examine the nature of changes in hippocampal firing patterns during object sampling, we computed object selectivity indices (SI; see Materials and Methods) for the mPFC Control (no treatment plus saline) group and a combination of the bilateral and ipsilateral $\mathrm{mPFC}$ inactivation groups that were equivalently affected by the treatments. Using a threshold of SI = 0.3 for separating neurons that were stable versus changed in object selectivity, the proportion of increased and decreased SIs in the Control condition were approximately equal $(n=32 / 246$, $13 \%$ increased; $n=36 / 246,15 \%$ decreased). In the combined bilateral and ipsilateral mPFC inactivation conditions, a similar proportion of hippocampal neurons increased in selectivity $(n=$ $17 / 117,14.5 \%)$. However, more than double that proportion of hippocampal neurons $(n=35 / 117,30 \%)$ decreased in selectivity (14 of these neurons nearly ceased firing during object sampling in session 2; these cells were not lost, as confirmed by observation of their waveforms during the course of that session), such that the proportions of increased and decreased SIs were not equivalent (binomial $p=0.0049$ ). Furthermore, a $\chi^{2}$ test on the overall distribution of stable, increased, and decreased SIs revealed that SIs were significantly reduced in the combination of the bilateral and ipsilateral mPFC inactivation conditions compared with the Control condition $\left(\chi^{2}=12.2934, d f=5, p=0.002\right)$. This observation indicates that $\mathrm{mPFC}$ plays a specific role in retrieval of context-appropriate object-location representations by hippocampal neurons, and lacking $\mathrm{mPFC}$ input results in indiscriminate activation or no activation by a substantial fraction of these neurons. 
A

Session 1

Context A

Context B

Unit 1 MEC, SAL
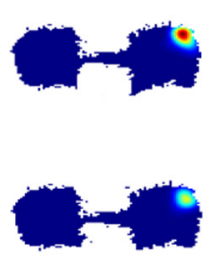

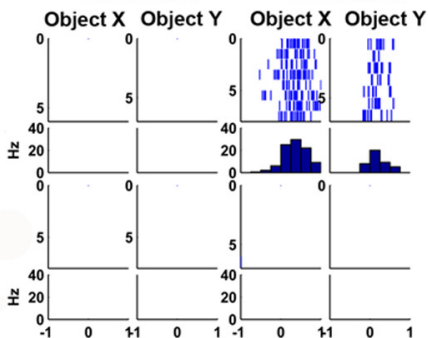

Unit 2 mPFC, SAL
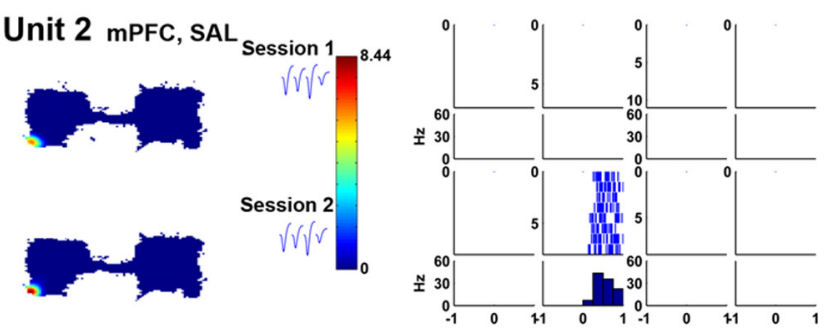

Unit 3 MEC, SAL
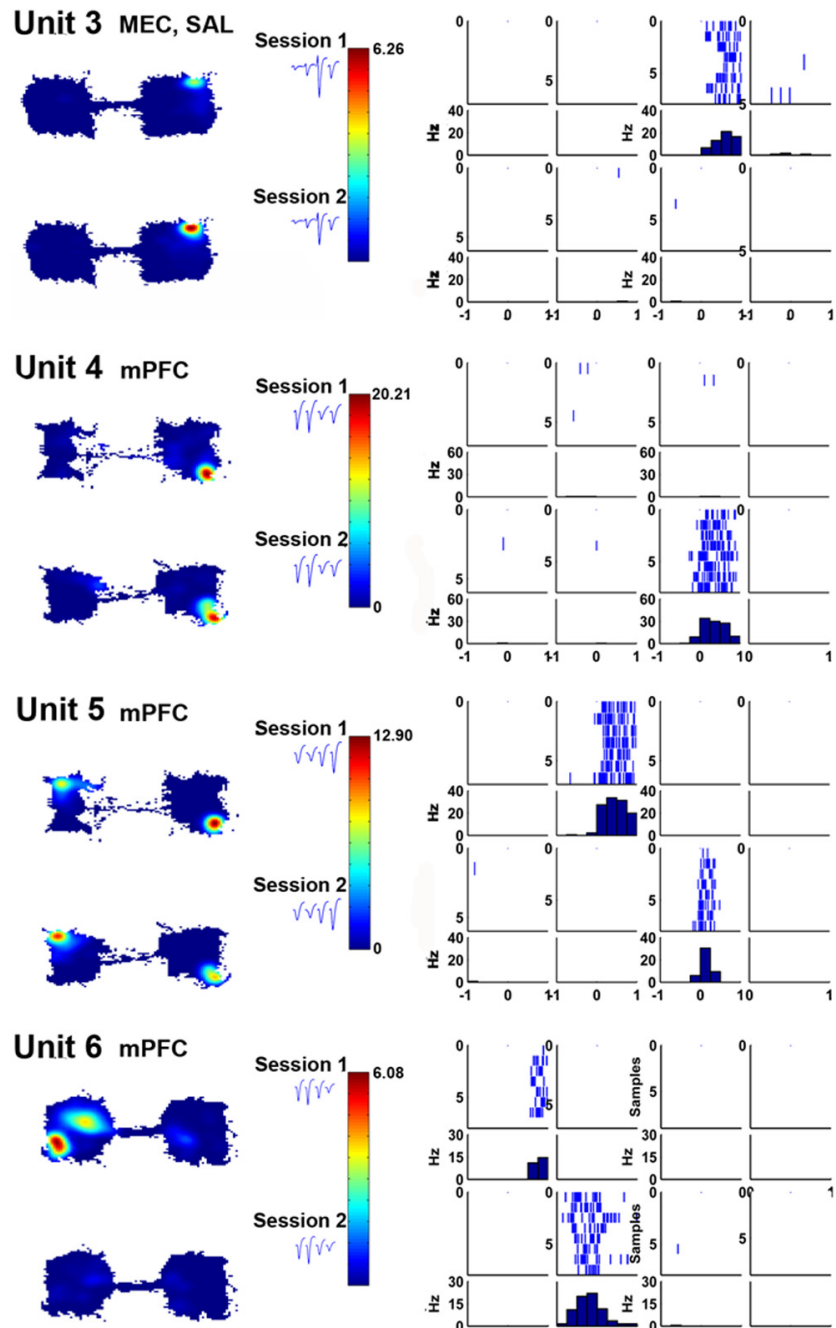

\section{Session 2}
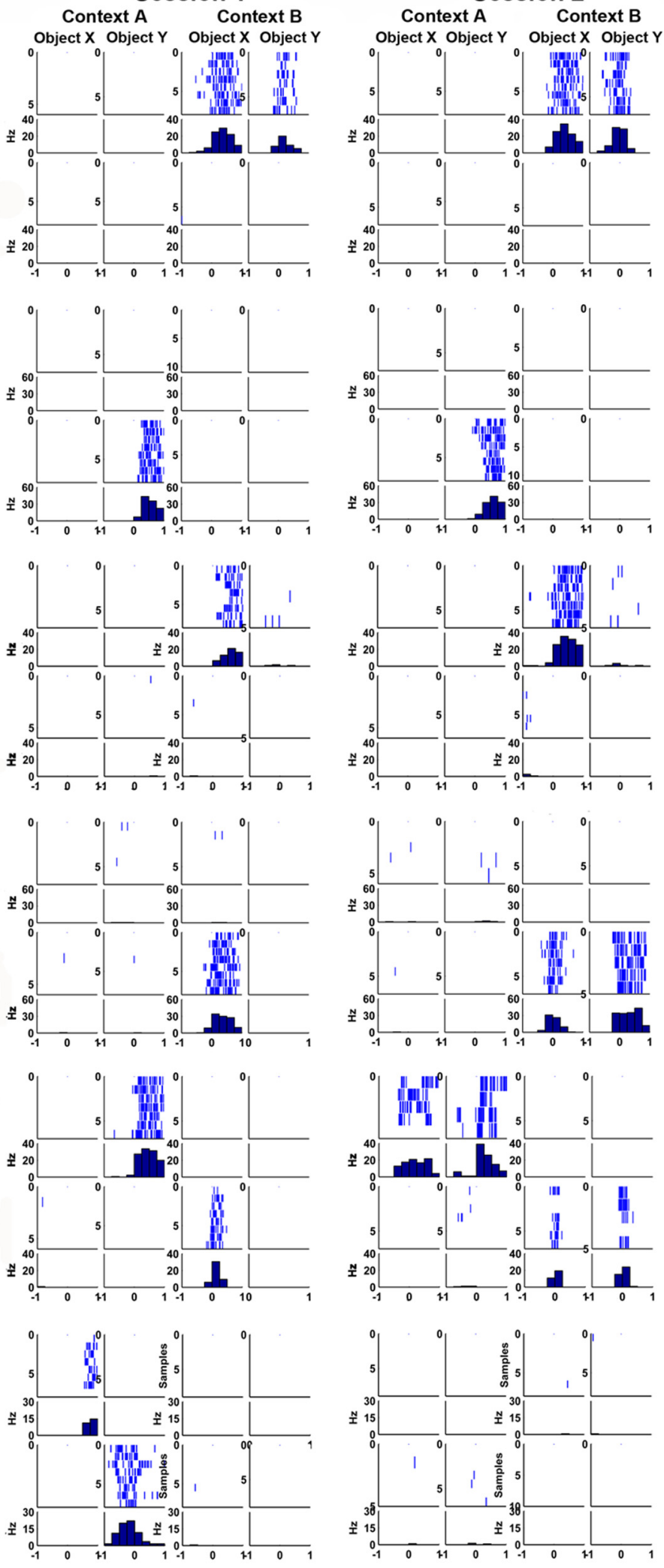

Time (ms)

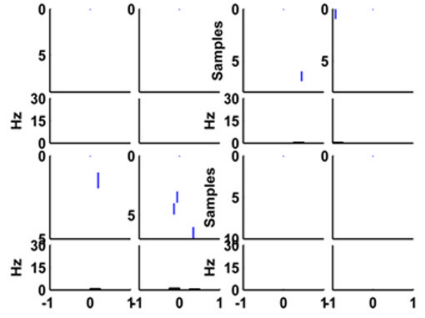

Time (ms)

Figure 4. Spatial firing rate maps and averaged tetrode waveforms during the entire session $(\boldsymbol{A})$ and rasters and peri-event histograms plotted for object-sampling events $(\boldsymbol{B})$ for each object $(X$ or $Y$ ) at each position (shown separately in upper and bottom) within each context (A or B) for example neurons that fired during the object-sampling period in each group. See descriptions of firing patterns in text. (Figure continues.) 
B

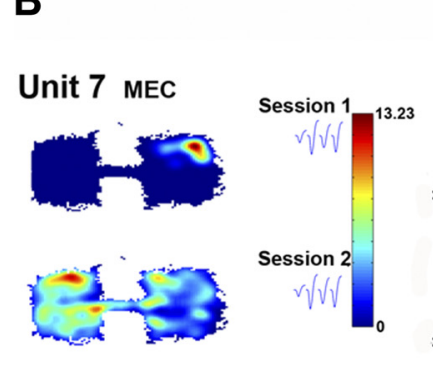

Session 1
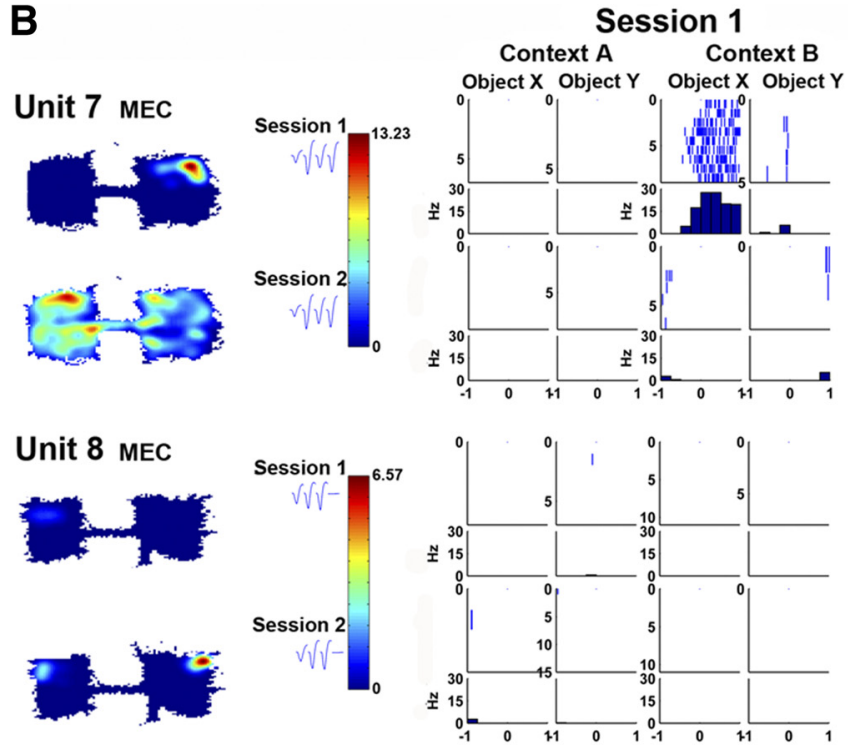
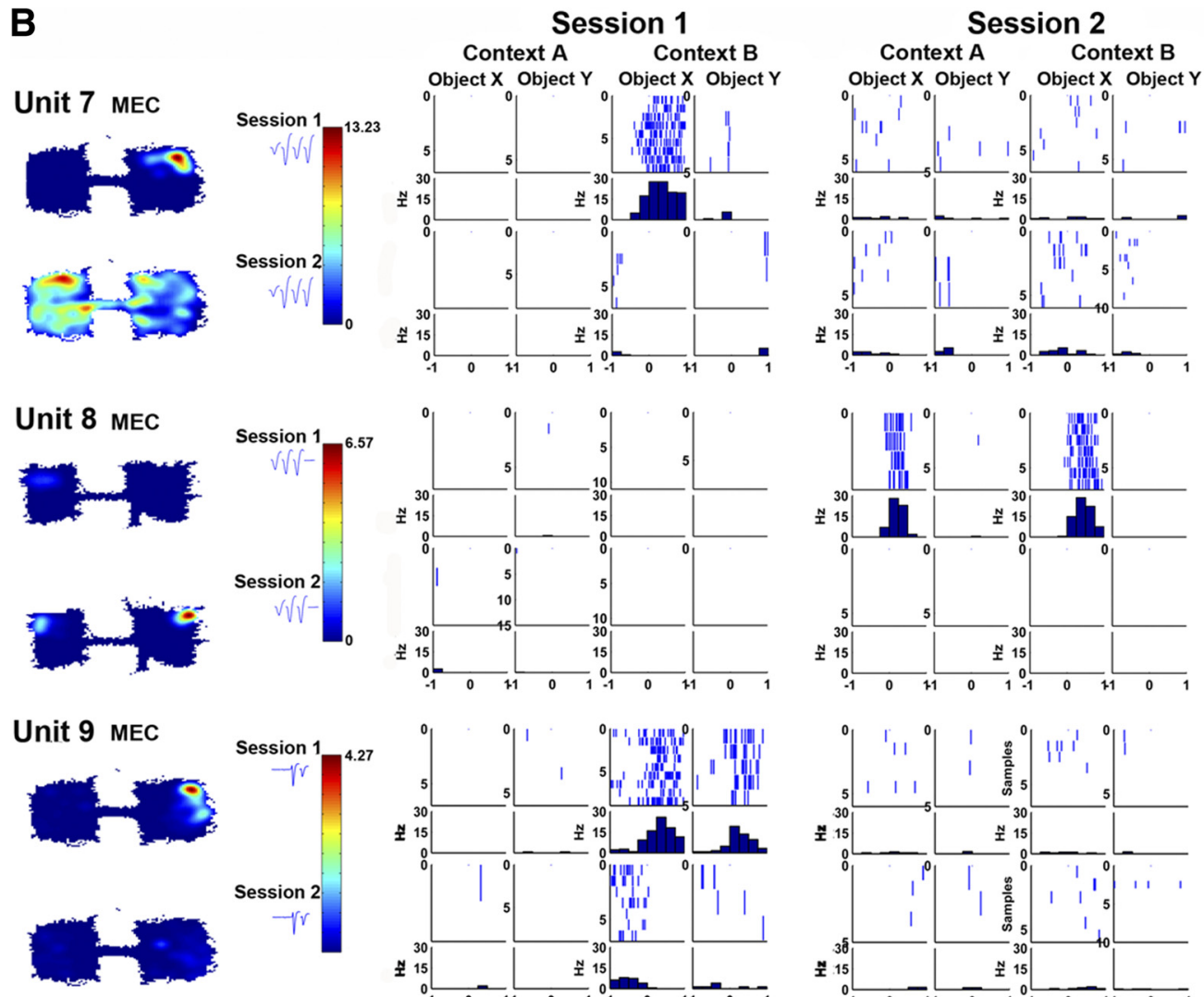

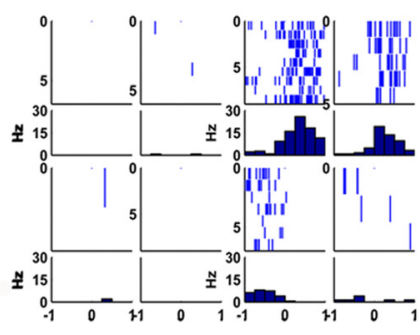

Time (ms)
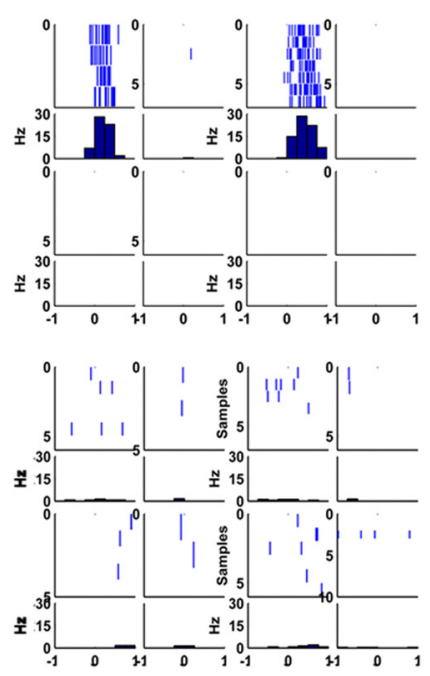

Time (ms)

Figure 4. (Figure continued.)

\section{MEC inactivation results in pervasive alternations in spatial representation}

Unlike after mPFC inactivation, MEC inactivation resulted in major alternations of spatial firing patterns of hippocampal neurons observed throughout the recording session. Figure 6 shows examples of place fields in both sessions across MEC and mPFC treatment conditions. Units 1 and 2 were from MEC control treatment sessions and each had stable place fields located in one context. Units 3-5 are examples of remapping after bilateral or unilateral MEC muscimol treatment (correlation coefficient $<0.58$ ). Some of these cells (Units 3 and 5) did not fire in one of the sessions (maximum firing rate $<0.2 \mathrm{~Hz}, 4.4 \pm 2.87 \%$ ) whereas other cells fired in distinct locations between the two sessions (Unit 4). These findings were in striking contrast to the observation that mPFC inactivation had little effect on the place fields of hippocampal neurons (Fig. 6).

We quantified the effects of MEC and MPFC inactivation on spatial representations of hippocampal neurons by comparing firing patterns before and after treatments during the separate period earlier in the trial when animals explored a context before presentation of the objects. First, we characterized six basic spatial firing properties for each cell in each session (selectivity, information, sparsity, maximum firing rate, mean firing rate, and place field size; Table 3). Saline infusions had no effect on any of these measures in either the MEC or the mPFC groups (all $p>$ $0.05)$. Bilateral, ipsilateral, and contralateral MEC inactivation each significantly reduced maximum firing rates of hippocampal neurons (bilateral: $z=4.32, p<0.001$; ipsilateral: $z=5.54, p<$ 0.001 ; contralateral: $z=2.10, p=0.034$ ), and ipsilateral MEC inactivation increased selectivity $(z=2.70, p=0.007)$, but no other spatial firing properties of hippocampal neurons were altered by MEC inactivation. Only bilateral inactivation of $\mathrm{mPFC}$ reduced the maximal firing rates of CA1 cells $(z=2.51, p=$ 0.012 ) and no other spatial firing properties of hippocampal neurons were affected by $\mathrm{mPFC}$ inactivation. These results indicate that the spatial firing rates of CA1 neurons are modulated by MEC but hardly by $\mathrm{mPFC}$, and other basic spatial firing properties are not dependent on either structure.

Second, we examined the effects of treatments on the locations of spatial representations (place fields). The majority of neurons $(78.15 \pm 5.62 \%)$ had place fields in either context with about $5.5 \pm 2.76 \%$ of all neurons in the first session located in the connection path. There was no significant difference in the proportion of neurons that had place fields in either context in the control groups (no treatment vs saline groups; $\chi^{2}=1.113, d f=1$, $p=0.292)$. The proportion of neurons that had place fields in either context significantly increased after bilateral $\left(\chi^{2}=33.14\right.$, $d f=1, p<0.0001)$, ipsilateral $\left(\chi^{2}=23.66, d f=1, p<0.0001\right)$, and contralateral $\left(\chi^{2}=58.05, d f=1, p<0.0001\right)$ MEC inactivation compared with the control group (Table 3 ). No significant differences were observed among MEC inactivation groups $(p>0.05)$.

To quantify the effects of MEC and MPFC inactivation on the locations of place fields of CA1 neurons we performed correlations between spatial firing patterns recorded throughout the first versus second sessions. As illustrated in Figure 5B, the distribution of spatial correlations in Control (combined no treatment and saline in both groups) conditions was clearly bimodal, with one peak approximately at a correlation coefficient of 0.05 and 

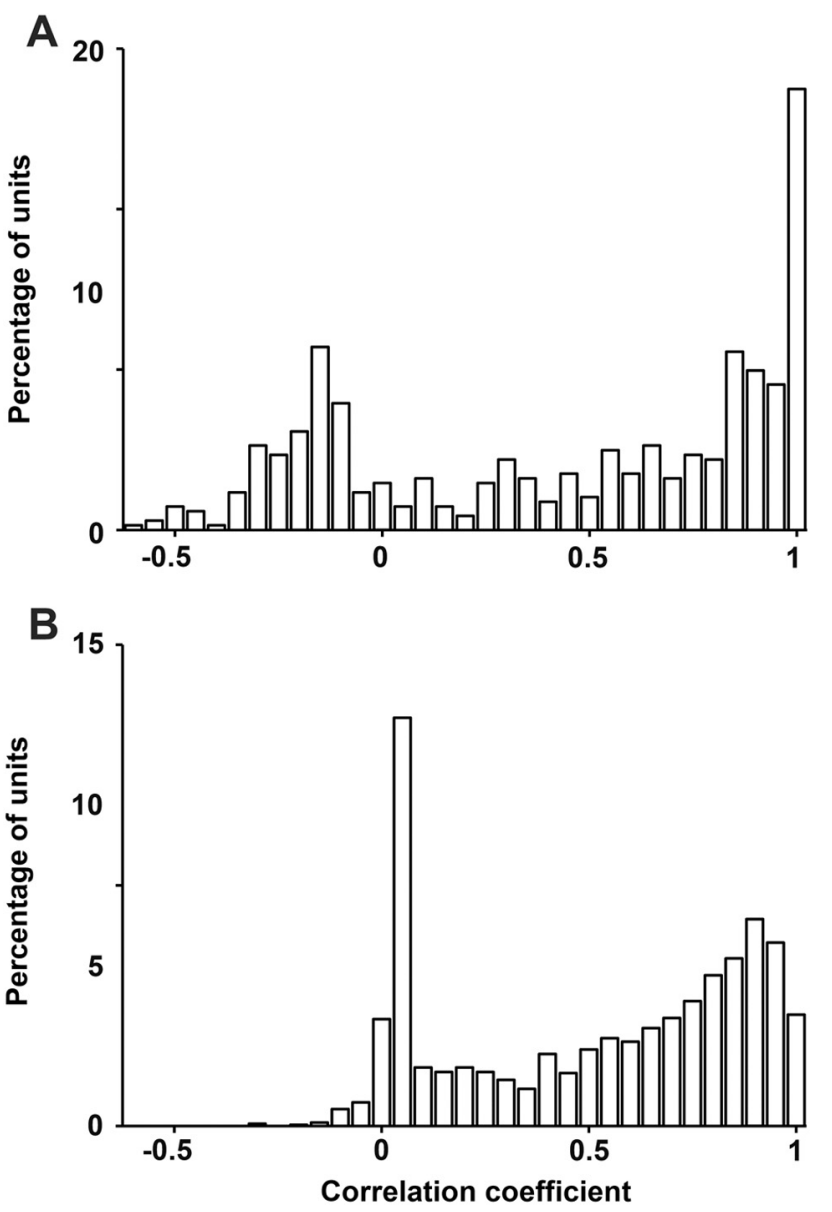

Figure 5. A, The distribution of correlation coefficients between object-sampling firing patterns in the two sessions for control (no treatment plus saline) MEC and mPFC groups. $\boldsymbol{B}$, The distribution of correlation coefficients between spatial firing rate maps in the two sessions for control MEC and mPFC groups.

the other at $\sim 0.9$. This pattern indicates that, as observed with object-sampling responses, neurons generally fell into two categories, those that were relatively stable between the two sessions and those that spatially remapped. To assess differences in the proportions of neurons between these two categories, an unsupervised K-means clustering algorithm was used to find the best threshold to separate between two cluster groups as $r=0.58$, and we designated neurons that had a correlation coefficient greater than that value as stable and neurons with correlations coefficients less than that threshold as remapped between sessions; then we used the $\chi^{2}$ tests to statistically compare the proportions across the experimental conditions within and between groups. Initially we compared no-treatment and saline-treated groups and found no difference between these conditions for the MEC $\left(\chi^{2}=0.337, d f=1, p=0.561\right)$ group with overall stability of $76 \%$ $(n=304)$. In the mPFC group, saline treatment did reduce spatial correlations significantly $(n=162 / 212 ; 76.4 \%$ stable in the no treatment condition vs $n=146 / 223 ; 65.5 \%$ stable in the saline condition; $\left.\chi^{2}=6.456, d f=1, p=0.011\right)$. Therefore, to be conservative in the subsequent analyses, we compared all muscimoltreated conditions to the corresponding saline condition only.

$\chi^{2}$ tests that compared conditions (saline, bilateral, ipsilateral, and contralateral) showed that the proportions of neurons that had stable versus remapped spatial firing patterns varied among MEC conditions $\left(\chi^{2}=35.245, d f=3, p<0.0001\right)$. In subsequent post hoc $\chi^{2}$ tests, striking shifts toward spatial remapping were observed following inactivation of MEC compared with the saline condition ( $n=131 / 169 ; 77.5 \%$ stable) following bilateral $\left(n=119 / 264 ; 45.1 \%\right.$ stable; $\left.\chi^{2}=28.274, d f=1, p<0.001\right)$, ipsilateral ( $n=138 / 280 ; 49.3 \%$ stable; $\chi^{2}=27.197, d f=1, p<$ $0.001)$, and contralateral $\left(n=135 / 263 ; 51.3 \%\right.$ stable; $\chi^{2}=$ 23.109, $d f=1, p<0.001)$ MEC inactivation. In the mPFC group, comparison among conditions (saline, bilateral, ipsilateral, and contralateral) identified no differences between conditions $\left(\chi^{2}=\right.$ 1.056, $d f=3, p<0.7878)$. Post hoc tests that used the saline control as comparison indicated no significant changes in stability for the bilateral $\left(\chi^{2}=1.094, d f=1, p=0.296\right)$, ipsilateral $\left(\chi^{2}=0.310, d f=1, p=0.578\right)$, or contralateral $\left(\chi^{2}=0.412, d f=\right.$ $1, p=0.521) \mathrm{mPFC}$ conditions. Remapping of place fields was significantly greater following MEC inactivation than following mPFC inactivation in bilateral $\left(\chi^{2}=6.658, d f=1, p<0.01\right)$ and ipsilateral $\left(\chi^{2}=4.345, d f=1, p<0.05\right)$ inactivation conditions, and approached significance in the contralateral $\left(\chi^{2}=2.931\right.$, $d f=1, p=0.087)$ inactivation condition. Thus, CA1 spatial firing patterns were highly dependent on MEC but not mPFC.

\section{MEC inactivation also causes pervasive reorganization of object-position representations}

In the MEC group, 350 neurons (29\% of the total neurons recorded) significantly increased firing during object sampling (Table 2). MEC inactivation produced substantial changes in hippocampal responses during object sampling, but the pattern of responses differed strikingly from that following $\mathrm{mPFC}$ inactivation. For example, in Figure 4, Unit 7, had a clear place field and object-position selectivity in session 1, but after bilateral MEC inactivation, lost its spatial firing pattern and object-sampling selectivity in session 2 . Unit 8 was not active in session 1, but after bilateral MEC inactivation, developed place fields at the object-sampling positions and fired highly selectively during sampling of object $\mathrm{X}$ in the upper position of both contexts in session 2. In session 1, Unit 9 fired selectively during object sampling in Context B, but in session 2 lost both its spatial and object-sampling selectivity.

The neurons in MEC Control and MEC treatment groups were designated to be either stable or unstable using the same threshold value based on correlation coefficients as described above. An overall $\chi^{2}$ analysis revealed significant differences between the conditions in MEC group $\left(\chi^{2}=26.6678, d f=3, p<0.0001\right)$. Significant alterations in response patterns during sampling bouts were observed compared with the MEC Control condition following bilateral ( $n=33 / 79 ; 41.8 \%$ stable; $\left.\chi^{2}=33.967, d f=1, p<0.0001\right)$, ipsilateral $(n=40 / 75 ; 53.4 \%$ stable; $\left.\chi^{2}=16.657, d f=1, p<0.0001\right)$, and contralateral $(n=52 / 80$; $65 \%$ stable; $\left.\chi^{2}=6.355, d f=1, p<0.05\right)$ MEC inactivation. No significant difference was observed between bilateral and ipsilateral MEC inactivation conditions $\left(\chi^{2}=1.836, d f=1, p=0.175\right)$. However, the bilateral and contralateral MEC inactivation conditions did differ $\left(\chi^{2}=\right.$ $8.01, d f=1, p<0.01)$. These findings indicate that MEC inactivation alters firing patterns of CA1 neurons not only during context exploration but also during object-sampling periods.

In contrast to the prevalence of decreases in object selectivity following bilateral or ipsilateral $\mathrm{mPFC}$ inactivation, after MEC inactivation, changes in hippocampal firing patterns often involved increases (Fig. 4, Unit 8) as well as decreases (Fig. 4, Units 7 and 9) of responses at multiple object-sampling locations, suggesting an overall reorganization of the object-location mappings. In 117 neurons in which selectivity indices could be obtained before and after MEC inactivation, more hippocampal neurons gained in object selectivity $(n=51 / 154 ; 33 \%)$ than lost 
MEC

\section{Session 1}
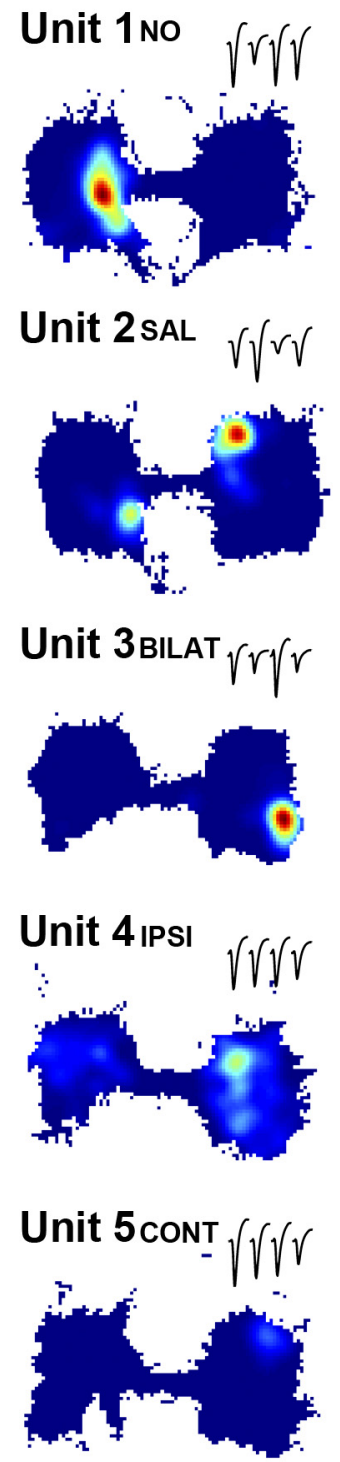

Session 2

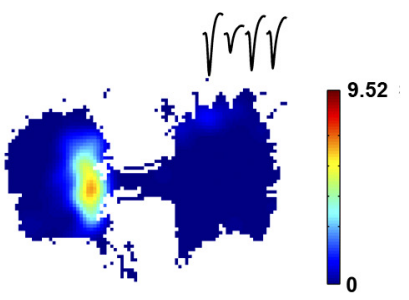

$\checkmark \sqrt{v V}$
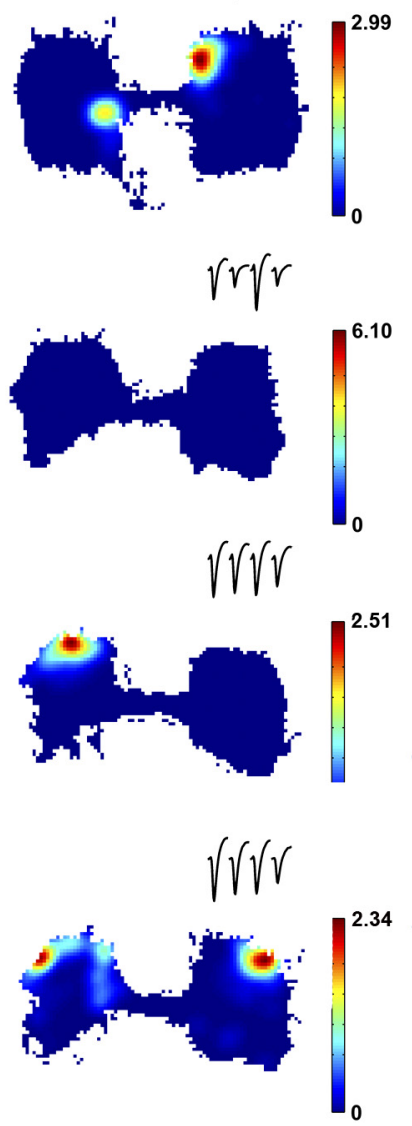

MPFC
Session 1

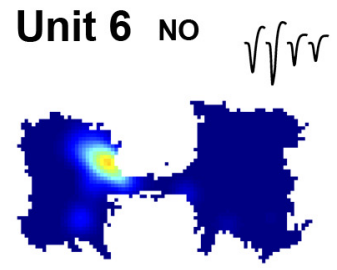

Unit 7 SAL $\quad \sqrt{ } \sqrt{ } \sqrt{ }$

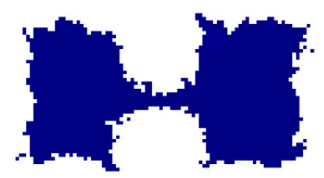

Unit 8 BILAT $V \bigvee V \gamma$

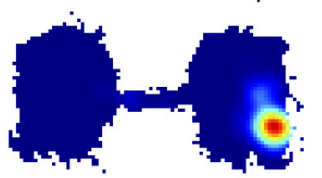

Unit 9 IPSI $\sqrt{ } \mathfrak{f} V$

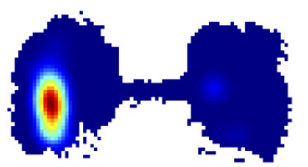

Unit 10 cont $\sqrt{ } \sqrt{ } \sqrt{ } \int$

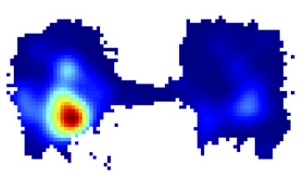

Session 2

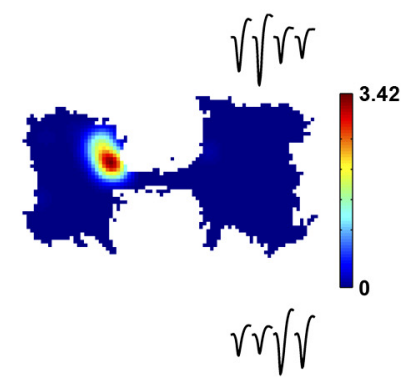

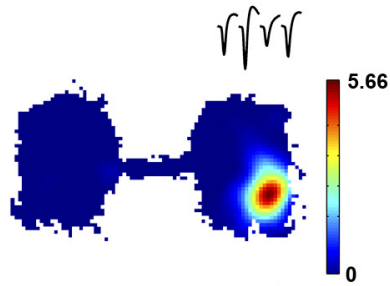

$\sqrt{ } p v$
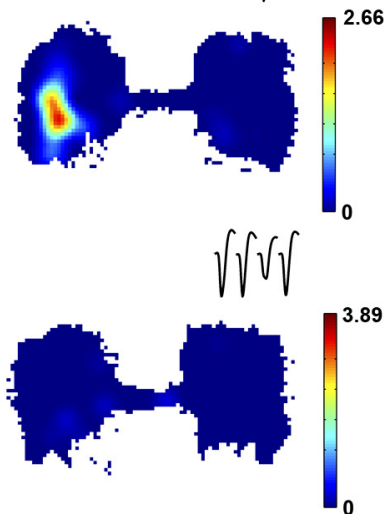

Figure 6. Example spatial firing maps and tetrode waveforms of CA1 place cells in MEC and mPFC groups. Color bars on the right represent firing rates (in Hz). Units 1 and 6 are examples where no treatment was performed and Units 2 and 7 are examples where saline was infused between two sessions. Units 1, 2, and 6 of neurons had stable spatial firing maps (correlation coefficients $>$ 0.58 ) between sessions, whereas Unit 7 is an example where the cell developed place fields in the second session. Units $3-5$ are examples of neurons that remapped (correlation coefficients $<0.58$ ) after bilateral (unit 3), ipsilateral (unit 4), or contralateral (unit 5) MEC inactivation. Units 8 and 9 are examples of neurons that were stable after mPFC bilateral or ipsilateral inactivation, respectively, whereas Unit 10 is an example of the occasional loss of spatial firing after a contralateral mPFC inactivation.

object selectivity $(n=35 / 154 ; 22.7 \%)$ between sessions (binomial $p=0.0195)$.

Finally, we compared the proportion of the neurons that had either gained or lost object selectivity at a particular location and context between mPFC and MEC combined bilateral plus ipsilateral inactivation groups. As described above, in Control conditions, many hippocampal neurons fire selectively during the sampling of one of the objects at a particular position, and relatively few and equivalent numbers of neurons decrease or increase their selectivity for a particular object. Furthermore, the distributions of gains and losses of object selectivity did not differ between the MEC versus mPFC Control conditions $\left(\chi^{2}=0.013\right.$, $d f=1, p=0.9099$ ). However, here we observed that more hippocampal neurons gained object selectivity in the combined
MEC inactivation conditions (Fig. 4, Unit 8) whereas more hippocampal neurons lost selectivity in the combined $\mathrm{mPFC}$ inactivation conditions (Fig. 4, Units $4-6 ; \chi^{2}=9.18, d f=1, p<0.01$; Fig. 7). Thus, while both $\mathrm{mPFC}$ and MEC contribute to hippocampal neuron firing patterns during object sampling, the nature of these contributions differs. The mPFC is essential to retrieval of specific object-location representations that predict performance (Komorowski et al., 2009), whereas MEC plays a global role in mapping object and location information.

\section{Discussion}

There has been considerable recent interest in the nature of functional interactions between the hippocampus and PFC as well as entorhinal cortex. Here the results show that mPFC and MEC 
Table 3. Basic properties of place cells in MEC and mPFC group

\begin{tabular}{|c|c|c|c|c|c|c|c|c|}
\hline & Selectivity & Sparsity & $\begin{array}{l}\text { Information } \\
\text { (bits) }\end{array}$ & $\begin{array}{l}\text { Size } \\
\text { (bins) }\end{array}$ & $\begin{array}{l}\text { Maximum rate } \\
(\mathrm{Hz})\end{array}$ & $\begin{array}{l}\text { Mean rate } \\
(\mathrm{Hz})^{a}\end{array}$ & $\begin{array}{l}\text { Number of } \\
\text { place fields }\end{array}$ & $\begin{array}{l}\text { Number of } \\
\text { neurons }^{b}\end{array}$ \\
\hline \multicolumn{9}{|c|}{ MEC inactivation } \\
\hline NO & $\begin{array}{c}18.09 \pm 5.52 / \\
19.33 \pm 7.58\end{array}$ & $\begin{array}{l}0.31 \pm 0.14 / \\
0.34 \pm 0.13\end{array}$ & $\begin{array}{l}4.51 \pm 1.55 / \\
\quad 4.32 \pm 1.55\end{array}$ & $\begin{array}{l}215.5 \pm 97.5 / \\
215.6 \pm 100.4\end{array}$ & $\begin{array}{r}2.38 \pm 1.53 / \\
2.15 \pm 1.35\end{array}$ & $\begin{array}{c}1.29 \pm 0.98 / \\
1.23 \pm 0.95\end{array}$ & $\begin{array}{l}1.00 / \\
1.01\end{array}$ & $\begin{array}{l}211 / \\
213\end{array}$ \\
\hline SAL & $\begin{array}{c}17.97 \pm 7.53 / \\
18.48 \pm 5.57\end{array}$ & $\begin{array}{l}0.30 \pm 0.14 / \\
0.32 \pm 0.14\end{array}$ & $\begin{array}{l}4.51 \pm 1.35 / \\
4.43 \pm 1.51\end{array}$ & $\begin{array}{c}224.3 \pm 117.3 / \\
213.4 \pm 96.0\end{array}$ & $\begin{array}{l}2.37 \pm 1.23 / \\
2.28 \pm 1.33\end{array}$ & $\begin{array}{c}1.27 \pm 1.01 / \\
1.32 \pm 1.09\end{array}$ & $\begin{array}{l}1.06 / \\
1.09\end{array}$ & $\begin{array}{l}166 / \\
162\end{array}$ \\
\hline BILAT & $\begin{array}{l}17.18 \pm 9.29 / \\
19.29 \pm 13.44\end{array}$ & $\begin{array}{c}0.38 \pm 0.18 / \\
0.41 \pm 0.19\end{array}$ & $\begin{array}{r}4.43 \pm 1.65 / \\
4.34 \pm 2.14\end{array}$ & $\begin{array}{l}265.2 \pm 160.6 / \\
246.8 \pm 171.7\end{array}$ & $\begin{array}{l}2.55 \pm 1.59 / \\
\quad 1.96 \pm 1.52^{* *}\end{array}$ & $\begin{array}{l}1.37 \pm 1.01 / \\
1.32 \pm 1.09\end{array}$ & $\begin{array}{l}0.98 / \\
0.98\end{array}$ & $\begin{array}{l}233 / \\
217^{c}\end{array}$ \\
\hline IPSI & $\begin{array}{l}15.55 \pm 6.42 / \\
\quad 18.06 \pm 11.12^{* *}\end{array}$ & $\begin{array}{l}0.42 \pm 0.15 / \\
0.46 \pm 0.19\end{array}$ & $\begin{array}{c}4.21 \pm 1.55 / \\
4.56 \pm 1.99\end{array}$ & $\begin{array}{l}240.4 \pm 118.3 / \\
219.0 \pm 129.2\end{array}$ & $\begin{array}{l}2.66 \pm 1.59 / \\
\quad 1.89 \pm 1.52^{* *}\end{array}$ & $\begin{array}{c}1.37 \pm 1.00 / \\
0.95 \pm 1.02\end{array}$ & $\begin{array}{l}0.97 / \\
1.04\end{array}$ & $\begin{array}{l}245 / \\
267^{c}\end{array}$ \\
\hline CONT & $\begin{array}{l}17.94 \pm 11.42 / \\
18.46 \pm 12.33\end{array}$ & $\begin{array}{c}0.36 \pm 0.20 / \\
0.39 \pm 0.16\end{array}$ & $\begin{array}{c}4.80 \pm 2.43 / \\
5.07 \pm 2.74\end{array}$ & $\begin{array}{l}216.5 \pm 117.5 / \\
229.5 \pm 149.9\end{array}$ & $\begin{array}{l}2.18 \pm 1.61 / \\
\quad 1.90 \pm 1.45^{*}\end{array}$ & $\begin{array}{c}1.30 \pm 0.99 / \\
1.11 \pm 0.97\end{array}$ & $\begin{array}{l}1.00 / \\
0.96\end{array}$ & $\begin{array}{l}222 / \\
202^{c}\end{array}$ \\
\hline \multicolumn{9}{|c|}{ mPFC inactivation } \\
\hline NO & $\begin{array}{l}17.18 \pm 8.02 / \\
18.16 \pm 6.18\end{array}$ & $\begin{array}{l}0.30 \pm 0.11 / \\
0.32 \pm 0.10\end{array}$ & $\begin{array}{c}4.55 \pm 1.43 / \\
4.29 \pm 1.46\end{array}$ & $\begin{array}{l}207.8 \pm 91.8 / \\
203.0 \pm 93.1\end{array}$ & $\begin{array}{l}1.78 \pm 1.06 / \\
7.76 \pm 1.04\end{array}$ & $\begin{array}{c}1.34 \pm 1.09 / \\
1.39 \pm 1.14\end{array}$ & $\begin{array}{l}1.01 / \\
0.95\end{array}$ & $\begin{array}{l}193 / \\
180\end{array}$ \\
\hline SAL & $\begin{array}{l}17.72 \pm 12.74 / \\
17.47 \pm 11.82\end{array}$ & $\begin{array}{r}0.22 \pm 0.08 / \\
0.22 \pm 0.06\end{array}$ & $\begin{array}{l}4.21 \pm 1.54 / \\
4.55 \pm 2.00\end{array}$ & $\begin{array}{l}197.3 \pm 71.4 / \\
194.8 \pm 70.4\end{array}$ & $\begin{array}{l}2.18 \pm 1.38 / \\
2.29 \pm 1.44\end{array}$ & $\begin{array}{c}1.29 \pm 0.95 / \\
1.31 \pm 1.05\end{array}$ & $\begin{array}{l}1.05 / \\
1.02\end{array}$ & $\begin{array}{l}210 / \\
204\end{array}$ \\
\hline BILAT & $\begin{array}{c}17.78 \pm 9.70 / \\
19.01 \pm 9.90\end{array}$ & $\begin{array}{c}0.36 \pm 0.17 / \\
0.39 \pm 0.13\end{array}$ & $\begin{array}{r}4.31 \pm 1.65 / \\
4.40 \pm 1.76\end{array}$ & $\begin{array}{c}195.4 \pm 88.9 / \\
193.7 \pm 96.6\end{array}$ & $\begin{array}{l}2.08 \pm 1.23 / \\
1.77 \pm 1.26^{*}\end{array}$ & $\begin{array}{c}1.31 \pm 1.00 / \\
1.19 \pm 1.02\end{array}$ & $\begin{array}{l}0.97 / \\
1.01\end{array}$ & $\begin{array}{l}184 / \\
188\end{array}$ \\
\hline IPSI & $\begin{array}{c}18.63 \pm 8.58 / \\
18.26 \pm 12.54\end{array}$ & $\begin{array}{c}0.32 \pm 0.11 / \\
0.33 \pm 0.13\end{array}$ & $\begin{array}{c}4.71 \pm 1.92 / \\
5.02 \pm 2.09\end{array}$ & $\begin{array}{c}194.2 \pm 92.4 / \\
175.0 \pm 99.6\end{array}$ & $\begin{array}{c}1.95 \pm 1.17 / \\
1.75 \pm 1.26\end{array}$ & $\begin{array}{c}1.17 \pm 0.77 / \\
1.17 \pm 1.03\end{array}$ & $\begin{array}{l}1.04 / \\
0.99\end{array}$ & $\begin{array}{l}142 / \\
134\end{array}$ \\
\hline CONT & $\begin{array}{c}16.05 \pm 6.01 / \\
17.45 \pm 10.06\end{array}$ & $\begin{array}{c}0.35 \pm 0.13 / \\
0.35 \pm 0.12\end{array}$ & $\begin{array}{r}4.47 \pm 1.72 / \\
5.04 \pm 2.12\end{array}$ & $\begin{array}{r}192.6 \pm 113.7 / \\
179.8 \pm 99.0\end{array}$ & $\begin{array}{c}1.86 \pm 1.19 / \\
1.61 \pm 1.13\end{array}$ & $\begin{array}{c}1.26 \pm 0.98 / \\
1.13 \pm 1.02\end{array}$ & $\begin{array}{l}1.07 / \\
1.07\end{array}$ & $\begin{array}{l}130 / \\
128\end{array}$ \\
\hline
\end{tabular}

Data are presented in session $1 /$ session 2 format. ${ }^{*} p<0.05$; $^{* *} p<0.01$.

${ }^{a}$ Computed from averaging spatial firing rates over every bin in the place field area.

${ }^{b}$ Place fields could be located in either or both contexts.

${ }^{c_{p}}<0.01$ against no treatment and saline group. NO, No injection; SAL, saline injection; BILAT, bilateral muscimol injection; IPSI, ipsilateral muscimol injection; CONT, contralateral muscimol injection.

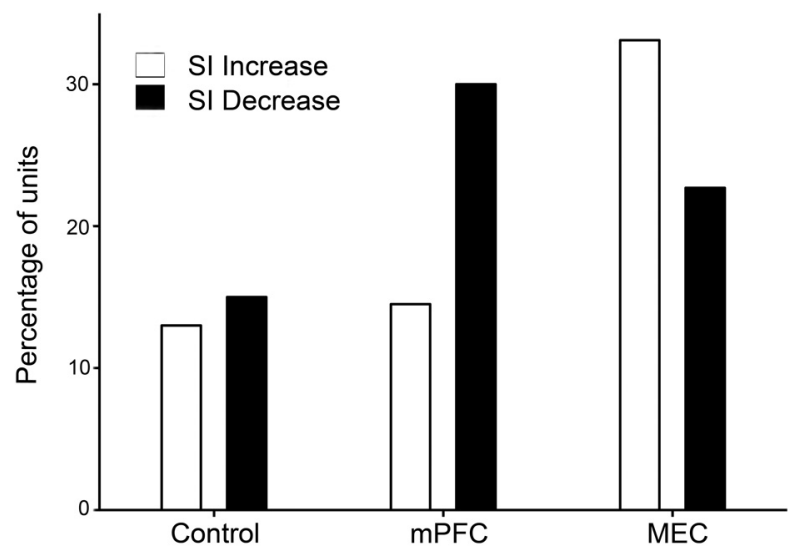

Figure 7. Comparison of the percentage of object-sampling neurons that increased or decreased in object selectivity index (SI) in Controls and following mPFC or MEC inactivation.

play distinct roles in the retrieval of contextualized memory representations in the hippocampus, such that $\mathrm{mPFC}$ provides critical rule-based contextual control over the retrieval of object-location memories whereas the MEC provides information critical to the hippocampal mapping of the spatial context including where important events occur.

Previous studies in animals have emphasized the flow of information from the hippocampus to the mPFC, which then uses the memories to guide behavior (Hasselmo, 2005; Colgin, 2011; Gordon, 2011). The present findings indicate a critical role for the opposite direction of communication by which the mPFC influences hippocampal information processing, consistent with studies that emphasize prefrontal top-down executive control of memory retrieval (Dobbins et al., 2002). The mPFC sends projections to the hippocampus via parahippocampal areas (Burwell and Amaral, 1998) and via the nu- cleus reunions (Vertes, 2002). Notably, the effects of mPFC inactivation are selective to hippocampal processing of object information and not to hippocampal spatial firing patterns, a finding that is consistent with anatomical evidence that $\mathrm{mPFC}$ projections to parahippocampal areas are primarily to perirhinal and lateral entorhinal cortex (Apergis-Schoute et al., 2006), areas known to process object information (Young et al., 1997; Wan et al., 1999) and not spatial information (Hargreaves et al., 2005). Also, because mPFC inactivation had little effects on hippocampal spatial representations, an influence primarily via MEC is unlikely.

In the majority of object-sampling neurons whose activity was affected by mPFC inactivation, the reduction in selectivity involved robust responses indifferently to both objects, unlike the lack of object-related firing observed early in training (Komorowski et al., 2009). These findings suggest that the mPFC plays its role in part by suppressing the retrieval of alternative object associations that would be appropriate in a different context, consistent with the view that the PFC exerts its executive control via inhibition of irrelevant memories (Depue, 2012). We also observed that some previously selective object-sampling responses disappeared following $\mathrm{MPFC}$ inactivation, indicating that $\mathrm{mPFC}$ also plays a role in retrieving hippocampal memory representations. Corresponding to the reduction in specific object-location representations by hippocampal neurons, mPFC inactivation also increased investigation time and errors in judgments about the object-location associations. This combination of results favors the view that the PFC does not contribute to hippocampal spatial representations, but exerts a critical control over the retrieval and selection of specific object-location associations by hippocampal neural ensembles, consistent with the view that PFC biases the retrieval of context appropriate memories (Cohen et al., 1996; Miller, 1999). Prefrontal inputs to the hippocampus could also play a role in the formation of hip- 
pocampal memory-related firing patterns during the acquisition or expression of task rules (Rich and Shapiro, 2009).

MEC function is also critical to the retrieval of hippocampal object-location associations, but it plays a qualitatively different role than that of mPFC. Since the discovery of "grid cells" in MEC, neurons that exhibit spatially periodic firing patterns (Moser et al., 2008), studies have sought to clarify whether the MEC is the source of spatial information to the hippocampus or whether outputs of the hippocampus influence MEC spatial coding. Lesions of MEC layer III, which projects directly to CA1, result in larger and more dispersed spatial firing patterns of CA1 neurons (Brun et al., 2008) whereas lesions that disconnect CA1 from the indirect pathway from MEC via the dentate gyrus and CA3 have no effect on CA1 place fields (McNaughton et al., 1989; Brun et al., 2002). Larger lesions of the entorhinal cortex reduced CA1 firing rates and place field size and stability (Van Cauter et al., 2008). Importantly, none of these interruptions of MEC input eliminated spatial firing patterns of CA1 neurons, indicating that there are multiple sources of spatial signals used by the hippocampus and elimination of one input results in alteration rather than elimination of spatial firing. Notably, hippocampal lesions reduce the stability and other spatial firing characteristics of MEC neurons (Fyhn et al., 2004), so spatial representation throughout the MEC and hippocampus may be a product of both feedforward and feedback interactions between MEC and hippocampal subfields. The present findings are consistent with the results on permanent lesions of MEC, and extend these findings to show that temporary MEC inactivation alters place field properties and results in substantial remapping of CA1 place fields.

Importantly, MEC inactivation also affected the retrieval of contextualized object-memory representations, associated with overall changes in spatial firing patterns. This observation is likely secondary to the pervasive remapping of spatial representations, because our previous study showed that object-selective firing patterns are overlaid on pre-existing spatial representations in the form of increased activation during the sampling of a particular object at the preferred position (Komorowski et al., 2009). It is particularly interesting that MEC inactivation resulted in a disproportionate increase in object selectivity of hippocampal neurons, suggesting that the reduction of MEC inputs decreased the total spatial information input to hippocampal neurons and proportionately increased the influence of preserved object information from $\mathrm{mPFC}$ and elsewhere. These findings support the conclusion that alterations of hippocampal firing patterns during object sampling after MEC inactivation is secondary to pervasive spatial remapping rather than a reflection of failure in rule-based memory retrieval.

The present findings distinguish the effects of disconnection of pathways on neural activity patterns from their effects on behavioral performance. Thus, while bilateral inactivation of either MEC or mPFC was required to block performance, unilateral inactivation was consistently sufficient to alter hippocampal spatial or memory-related firing patterns even though task performance was unaffected. Previous studies have shown that $\mathrm{mPFC}$ lesions or inactivation do not affect simple odor, object, or spatial discrimination (Eichenbaum et al., 1983; Barker et al., 2007; Rich and Shapiro, 2007), so the effects of mPFC inactivation on object selectivity is unlikely due to an inability to discriminate the object stimuli. The present results show that the effects of inactivation of MEC or mPFC on neural activity cannot be attributed to loss of perceptual, motor, or motivational functions essential to perform the task, or to changes in behavior when the animals failed to perform accurately.

The proportion of neurons that were affected by mPFC or MEC inactivation was modest, leaving the majority of neuronal responses stable across recording sessions. It is remarkable that behavior was devastated even by these modest changes in hippocampal firing patterns when the inactivation was bilateral. It was also surprising that unilateral MEC inactivation, which affected both ipsilateral and contralateral CA1 spatial firing patterns, did not affect memory performance. These findings are reminiscent of a study showing that nearly complete remapping of spatial firing patterns by CA1 cells following changes in the color of the environment did not affect the animal's ability to find the goal location in a hippocampal-dependent spatial memory task (Jeffery et al., 2003). Conversely, cannabinoid treatment that impairs memory does not result in remapping of place cells, thus also dissociating hippocampal spatial firing patterns and spatial memory (Robbe and Buzsáki, 2009). It has been proposed that the partial remapping, as observed here, could spare sufficient intact spatial and context representation to support performance in spatial tasks (Anderson et al., 2006). An alternate possibility is that a behavioral deficit is observed only when internal processing or outputs from both sides of mPFC or MEC are inactivated, which could be more important than the total number of neurons affected.

The present findings also clarify the pathways involved within and between hemispheres in support of spatial and objectmemory representations within CA1. Previous studies have shown that the ipsilateral pathways between the mPFC and hippocampus are necessary and sufficient to support object-place memories (Warburton and Brown, 2010). Based on these findings we had expected that ipsilateral, but not contralateral, inactivation of MEC or mPFC would affect CA1 spatial and memory-related firing patterns. This expectation was confirmed for mPFC inactivation, wherein bilateral and ipsilateral inactivation similarly altered memory-related firing patterns but contralateral mPFC inactivation had no significant effect. However, bilateral, ipsilateral, and contralateral MEC inactivation all increased remapping of spatial firing patterns and it was predominantly when spatial remapping occurred that there was also remapping of the object-sampling firing patterns. These findings suggest that alterations of basic spatial firing properties and spatial remapping secondarily result in disruption of object memory-related firing patterns of CA1 neurons. In contrast, the role of mPFC inputs appears to be qualitatively different and much more selective. Bilateral mPFC inactivation, which produced a severe behavioral deficit, had no significant effect on basic spatial firing properties or place fields, indicating that hippocampal spatial representations per se are not sufficient to support performance in this task. These findings further support our conclusion that mPFC supports rule-based contextual retrieval and MEC supports spatial contextual representations via distinct mechanisms.

\section{References}

Allen TA, Narayanan NS, Kholodar-Smith DB, Zhao Y, Laubach M, Brown $\mathrm{TH}$ (2008) Imaging the spread of reversible brain inactivations using fluorescent muscimol. J Neurosci Methods 171:30-38. CrossRef Medline Anderson MI, Killing S, Morris C, O’Donoghue A, Onyiagha D, Stevenson R, Verriotis M, Jeffery KJ (2006) Behavioral correlates of the distributed coding of spatial context. Hippocampus 16:730-742. CrossRef Medline

Apergis-Schoute J, Pinto A, Paré D (2006) Ultrastructural organization of medial prefrontal inputs to the rhinal cortices. Eur J Neurosci 24:135-144. CrossRef Medline

Barker GR, Warburton EC (2011) When is the hippocampus involved in recognition memory? J Neurosci 31:10721-10731. CrossRef Medline

Barker GR, Bird F, Alexander V, Warburton EC (2007) Recognition memory for objects, place, and temporal order: a disconnection analysis of the role of the medial prefrontal cortex and perirhinal cortex. J Neurosci 27:2948-2957. Medline

Blumenfeld RS, Parks CM, Yonelinas AP, Ranganath C (2011) Putting the 
pieces together: the role of dorsolateral prefrontal cortex in relational memory encoding. J Cogn Neurosci 23:257-265. CrossRef Medline

Brun VH, Otnass MK, Molden S, Steffenach HA, Witter MP, Moser MB, Moser EI (2002) Place cells and place recognition maintained by direct entorhinal-hippocampal circuitry. Science 296:2243-2246. CrossRef Medline

Brun VH, Leutgeb S, Wu HQ, Schwarcz R, Witter MP, Moser EI, Moser MB (2008) Impaired spatial representation in CAl after lesion of direct input from entorhinal cortex. Neuron 57:290-302. CrossRef Medline

Buckner RL, Wheeler ME (2001) The cognitive neuroscience of remembering. Nat Rev Neurosci 2:624-634. CrossRef Medline

Burwell RD, Amaral DG (1998) Cortical afferents of the perirhinal, postrhinal, and entorhinal cortices of the rat. J Comp Neurol 398:179-205. CrossRef Medline

Cohen JD, Braver TS, O’Reilly RC (1996) A computational approach to prefrontal cortex, cognitive control and schizophrenia: recent developments and current challenges. Philos Trans R Soc Lond B Biol Sci 351: 1515-1527. CrossRef Medline

Colgin LL (2011) Oscillations and hippocampal-prefrontal synchrony. Curr Opin Neurobiol 21:467-474. CrossRef Medline

Depue BE (2012) A neuroanatomical model of prefrontal inhibitory modulation of memory retrieval. Neurosci Biobehav Rev 36:1382-1399. CrossRef Medline

Dickerson BC, Miller SL, Greve DN, Dale AM, Albert MS, Schacter DL, Sperling RA (2007) Prefrontal-hippocampal-fusiform activity during encoding predicts intraindividual differences in free recall ability: an event-related functional-anatomic MRI study. Hippocampus 17: 1060-1070. CrossRef Medline

Dobbins IG, Foley H, Schacter DL, Wagner AD (2002) Executive control during episodic retrieval: multiple prefrontal processes subserve source memory. Neuron 35:989-996. CrossRef Medline

Eichenbaum H, Clegg RA, Feeley A (1983) A re-examination of functional subdivisions of the rodent prefrontal cortex. Exp Neurol 79:434-451. CrossRef

Fyhn M, Molden S, Witter MP, Moser EI, Moser MB (2004) Spatial representation in the entorhinal cortex. Science 305:1258-1264. CrossRef Medline

Gordon JA (2011) Oscillations and hippocampal-prefrontal synchrony. Curr Opin Neurobiol 21:486-491. CrossRef Medline

Hargreaves EL, Rao G, Lee I, Knierim JJ (2005) Major dissociation between medial and lateral entorhinal input to dorsal hippocampus. Science 308: 1792-1794. CrossRef Medline

Hasselmo ME (2005) A model of prefrontal cortical mechanisms for goaldirected behavior. J Cog Neurosci 17:1115-1129. CrossRef Medline

Hasselmo ME, Giocomo LM, Brandon MP, Yoshida M (2010) Cellular dynamical mechanisms for encoding the time and place of events along spatiotemporal trajectories in episodic memory. Behav Brain Res 215: 261-274. CrossRef Medline

Hyman JM, Zilli EA, Paley AM, Hasselmo ME (2005) Medial prefrontal cortex cells show dynamic modulation with the hippocampal theta rhythm dependent on behavior. Hippocampus 15:739-749. CrossRef Medline

Jeffery KJ, Gilbert A, Burton S, Strudwick A (2003) Preserved performance in a hippocampal-dependent spatial task despite complete place cell remapping. Hippocampus 13:175-189. CrossRef Medline

Kim J, Delcasso S, Lee I (2011) Neural correlates of object-in-place learning in hippocampus and prefrontal cortex. J Neurosci 31:16991-17006. CrossRef Medline

Komorowski RW, Manns JR, Eichenbaum H (2009) Robust conjunctive item-place coding by hippocampal neurons parallels learning what happens where. J Neurosci 29:9918-9929. CrossRef Medline

Lee I, Solivan F (2008) The roles of the medial prefrontal cortex and hip- pocampus in a spatial paired-association task. Learn Mem 15:357-367. CrossRef Medline

MacDonald CJ, Lepage KQ, Eden UT, Eichenbaum H (2011) Hippocampal "time cells" bridge the gap in memory for discontiguous events. Neuron 71:737-749. CrossRef Medline

Manns JR, Eichenbaum H (2006) Evolution of declarative memory. Hippocampus 16:795-808. CrossRef Medline

McNaughton BL, Barnes CA, Meltzer J, Sutherland RJ (1989) Hippocampal granule cells are necessary for normal spatial learning but not for spatially-selective pyramidal cell discharge. Exp Brain Res 76:485-496. CrossRef Medline

Miller EK (1999) The prefrontal cortex: complex neural properties for complex behavior. Neuron 22:15-17. CrossRef Medline

Moser EI, Kropff E, Moser MB (2008) Place cells, grid cells, and the brain's spatial representation system. Annu Rev Neurosci 31:69-89. CrossRef Medline

Muir GM, Bilkey DK (2001) Instability in the place field location of hippocampal place cells after lesions centered on the perirhinal cortex. J Neurosci 21:4016-4025. Medline

Paxinos G, Watson C (2010) The rat brain in stereotaxic coordinates. Amsterdam: Elsevier.

Rich EL, Shapiro ML (2007) Prelimbic/infralimbic inactivation impairs memory for multiple task switches, not flexible selection of familiar tasks. J Neurosci 27:4747-4755. CrossRef Medline

Rich EL, Shapiro M (2009) Rat prefrontal cortical neurons selectively code strategy switches. J Neurosci 29:7208-7219. CrossRef Medline

Robbe D, Buzsáki G (2009) Alteration of theta timescale dynamics of hippocampal place cells by a cannabinoid is associated with memory impairment. J Neurosci 29:12597-12605. CrossRef Medline

Sauvage MM, Fortin NJ, Owens CB, Yonelinas AP, Eichenbaum H (2008) Recognition memory: opposite effects of hippocampal damage on recollection and familiarity. Nat Neurosci 11:16-18. CrossRef Medline

Sava S, Markus EJ (2008) Activation of the medial septum reverses agerelated hippocampal encoding deficits: a place field analysis. J Neurosci 28:1841-1853. CrossRef Medline

Simons JS, Spiers HJ (2003) Prefrontal and medial temporal lobe interactions in long-term memory. Nat Rev Neurosci 4:637-648. CrossRef Medline

Skaggs WE, McNaughton BL, Wilson MA, Barnes CA (1996) Theta phase precession in hippocampal neuronal populations and the compression of temporal sequences. Hippocampus 6:149-172. CrossRef Medline

Tomita H, Ohbayashi M, Nakahara K, Hasegawa I, Miyashita Y (1999) Topdown signal from prefrontal cortex in executive control of memory retrieval. Nature 401:699-703. CrossRef Medline

Treves A, Skaggs WE, Barnes CA (1996) How much of the hippocampus can be explained by functional constraints? Hippocampus 6:666-674. CrossRef Medline

Van Cauter T, Poucet B, Save E (2008) Unstable CA1 place cell representation in rats with entorhinal cortex lesions. Eur J Neurosci 27:1933-1946. CrossRef Medline

Vertes RP (2002) Analysis of projections from the medial prefrontal cortex to the thalamus in the rat, with emphasis on nucleus reuniens. J Comp Neurol 442:163-187. CrossRef Medline

Wan H, Aggleton JP, Brown MW (1999) Different contributions of the hippocampus and perirhinal cortex to recognition memory. J Neurosci 19: 1142-1148. Medline

Warburton EC, Brown MW (2010) Findings from animals concerning when interactions between perirhinal cortex, hippocampus and medial prefrontal cortex are necessary for recognition memory. Neuropsychologia 48:2262-2272. CrossRef Medline

Young BJ, Otto T, Fox GD, Eichenbaum H (1997) Memory representation within the parahippocampal region. J Neurosci 17:5183-5195. Medline 